\title{
The Practical Application of Cooperative Inquiry Model in the Teaching for Tibetan College Students
}

\author{
Shengyin Zhu \\ Key Laboratory of China's Ethnic Languages and Information Technology of Ministry of Education, Northwest Minzu \\ University, Lanzhou, Gansu 730000, China \\ Xiangzhen $\mathrm{He}$ \\ Key Laboratory of China's Ethnic Languages and Information Technology of Ministry of Education, Northwest Minzu \\ University, Lanzhou, Gansu 730000, China \\ Yerong $\mathrm{Hu}$ \\ Key Laboratory of China's Ethnic Languages and Information Technology of Ministry of Education, Northwest Minzu \\ University, Lanzhou, Gansu 730000, China \\ Yihao Zhang \\ Key Laboratory of China's Ethnic Languages and Information Technology of Ministry of Education, Northwest Minzu \\ University, Lanzhou, Gansu 730000, China
}

\begin{abstract}
The cooperative inquiry teaching mode refers to a teaching mode in which the teacher guides the students to learn the main knowledge points in the way of "independence, inquiry and cooperation" and communicate deeply through group inquiry, so as to better meet the requirements of cognitive and emotional goals in the course. The cooperative inquiry teaching mode is one of the effective models of English teaching, which focuses on students' learning and highlights the true, harmonious and efficient teaching concept. On the basis of practice, this paper discusses the specific application of cooperative inquiry teaching mode in English Teaching for Tibetan college students.
\end{abstract}

Index Terms - cooperative inquiry mode, classroom teaching, Tibetan College students

\section{INTRODUCTION}

With the development of the Belt and Road, the international exchanges in the western region are becoming more frequent (Ding Qun, 2018). Due to the influence of the Belt and Road, the enthusiasm of college students in English learning in ethnic minority areas has been greatly increasing. Many scholars have given more objective suggestions to minority college students in the process of learning English. But in the classroom teaching, there are few documents about how to improve the method of students' cooperative inquiry mode, especially in the cooperative inquiry mode, there are few documents about the teaching practice of ethnic minority college students, so this paper explores the cooperative inquiry mode for Tibetan college students in English teaching.

In order to cultivate students' autonomous learning, cooperative learning and inquiry learning, teachers should design activities with comprehensive, relevant and practical characteristics, so that students can acquire, interpret and judge the meaning of the text, express their personal views, intentions and emotions, analyze the similarities and differences of different cultures, develop multiple thinking and critical thinking, and improve learning ability and application ability through a series of activities integrating language, culture and thinking, such as learning, understanding, application, practice, migration and innovation. This requires teachers to change the bad, inefficient, mechanical and indoctrinated teaching mode, optimize the current learning mode, and advocate the learning activity view that emphasize student-oriented development and the combination of learning and application. The cooperative inquiry teaching mode is one of the effective learning methods for students.

Guided by modern education theory and constructivism learning theory, the cooperative inquiry teaching mode adheres to the concept of "student-oriented development ", highlights the idea of "cooperative inquiry", actively promotes classroom teaching reform, and solidly carries out the construction of efficient classroom mode. The purpose of "cooperative inquiry teaching mode" is to fully show the main role of students, to make students' learning more initiative, conscious, cooperative and creative, and to achieve the real transformation of students' learning mode. The cooperative inquiry teaching mode focuses on students' learning and highlights the true, harmonious and efficient teaching concept.. 


\section{The ReAlization of CoOPerative INQuiry Teaching Mode}

\section{A. Requirements for Teachers}

Cooperative inquiry teaching mode has higher requirements for teachers. First of all, teachers should change the traditional teaching ideas and methods, give up the dominant position in the classroom, return the initiative to the students, and make it clear that the role of teachers is to guide, inspire, help and answer questions. Secondly, teachers should improve their comprehensive ability. Teachers should not only improve teaching ability, but also update teaching theory, dare to practice, dare to innovate, and always focus on students' learning.

In the cooperative inquiry teaching mode, teachers' specific tasks in the classroom are to manage time, create atmosphere, organize teaching, regulate classroom and evaluate. (Zhang Duoshan, 2014)

(1) Time management: In the classroom, teachers should reduce the waste of time, put the limited classroom time into practice, and improve the utilization rate of time. At the same time, they should grasp the best time of the classroom, make good use of the first half of the classroom to solve the key problems and complete the main tasks.

(2) Atmosphere creating: Teachers are to establish a democratic and harmonious relationship between teachers and students, create a classroom atmosphere for cooperative learning, cultivate students' problem awareness and critical thinking, encourage students to dare to ask questions, and create an ideal teaching atmosphere for solving doubts.

(3) Teaching organization: Teachers are required to strengthen the management of classroom teaching, establish a "tense, orderly, serious and lively" classroom operation standard, guide students to actively participate in classroom task learning, perceptually experience, cooperatively explore, critically question, discuss and display, interact between teacher and students, etc. Students learn to mobilize the learning mood and attention in classroom teaching, and achieve the goal of "preparation before class, good state in class, and expansion after class".

(4) Classroom control: Teachers should have the ability to effectively control teaching time, teaching content, teaching rhythm, as well as unexpected "events" and "episodes" occurring in the classroom. This helps to make students focus their attention and arouse their enthusiasm. In addition, classroom regulation can also be carried out by teachers' tone, intonation, volume, evaluation, adjustment of teaching topics, change of teaching methods, etc.

(5)Feedback evaluation: Teachers should timely analyze and correct the students' classroom reaction, participation in learning, discussion, cooperation, exploration and knowledge acquisition in a class or a period of time, so as to prevent teaching deviation. Teachers should also make use of instant evaluation, self-evaluation of students and mutual evaluation of teachers and students to guide students to pay attention to the process of classroom learning, pay attention to the learning behavior of peers, and jointly improve the efficiency of classroom teaching.

\section{B. Requirements for Students}

\section{Group reasonably and effectively}

Students need to carry out group cooperation and exploration activities, so the reasonable and effective formation of the group is very important. Class students can be grouped according to character, learning ability, learning achievement, enthusiasm, participation, leadership, etc., with effective collocation, so that group members can learn from each other and ensure the comprehensive strength balance of each group. Each group has a more active classmate and a student with strong leadership as the team leader, and the obligations of each member in the group should be clear. Due to the strong practicality of group cooperative inquiry, after a period of cooperative learning, it is necessary to effectively adjust the cooperation among team members, so that students can truly achieve balanced development in learning. (Cai Yuqiu, 2014)

2. Strengthen students' sense of cooperation

In the traditional English teaching process, students are used to the learning method of "teachers teach and students listen", which leads to their lack of sufficient communication in the process of reading learning. Therefore, in the group cooperation and exploration activities, we must improve the students' sense of cooperation. If students do not have a good sense of cooperative inquiry, the efficiency of cooperative learning will be very low. In the process of daily teaching, teachers should try their best to enhance the interest of teaching, or add some reward mechanisms, strengthen the sense of cooperation of students, so that students have a correct understanding of group cooperative learning.

\section{SPECIFIC PRACTICE OF COOPERATIVE INQUIRY TEACHING MODE}

(Zhao Duoshan, 2014) thinks that the cooperative inquiry teaching mode should follow five links, that is, "introduction - task presentation - cooperative inquiry - student's presentation - summary and evaluation".

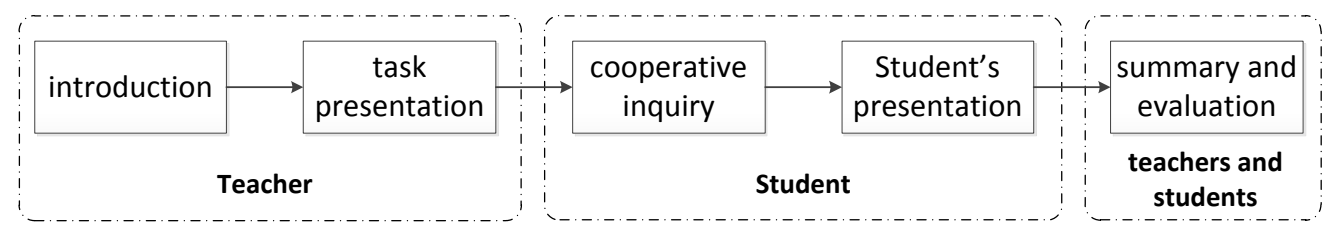

Cooperative inquiry teaching mode refers to a teaching mode in which the teacher guides the students in the teaching 
process, through autonomous learning of the main knowledge points in the way of "autonomy, inquiry and cooperation", and in-depth communication through group inquiry, so as to better achieve the requirements of cognitive and emotional goals in the curriculum. Among them, cognitive goals involve the knowledge, concepts, principles and abilities; emotional goals involve the cultivation of ideological feelings and moral qualities.

\section{A. Students Analysis}

The students are the Tibetan students in Northwest University for nationalities. Because their mother tongue is Tibetan, their English is relatively poor, so we choose the high school articles. Through the spot check, they found that they have mastered certain high school English vocabulary, and have some training for the reading of long articles and have mastered some reading strategies. The language difficulty of the articles read in this lesson is moderate. For them, the overall understanding is not difficult. Training students' cooperative inquiry ability has always been one of the main goals of teaching at home and abroad. The application of cooperative inquiry mode in the classroom can improve Tibetan students' English, broaden their mind, fully show their inquiry ability, make them realize the value of English learning and the importance of English for their future development.

\section{B. Teaching Content}

The teaching content is a short history of Western painting, a reading course of 6 Unit 1 art, which is an optional course for high school English. The reading part is an expository text, which introduces the art schools, art characteristics and some famous painters and works in different historical periods in the history of Western painting. The article is about 650 words.

\section{Teaching Aims}

(1) Students can understand the knowledge related to the brief history of Western painting. Through the teaching design, teachers should guide students to understand Western paintings in the different historical stages, appreciate the artistic charm of Western painting, and the differences between China and the West. It is necessary to supplement students with necessary cultural background knowledge to eliminate reading obstacles.

(2) Students can introduce the characteristics of the representative Western paintings in different periods and representative painters through group cooperation. Group discussion can expand and deepen the understanding of the article.

(3) Students can summarize the reasons for the diversity of Western painting forms through group research. After the discussion, the group members will find that they have expanded their knowledge, which can effectively improve their classroom learning efficiency.

\section{Key and Difficult Points of Teaching}

(1) Students understand the content of the article and can apply what they have learned.

(2) presentation and explanation of group cooperation.

(3) how to make students actively participate in the classroom activities of group cooperation and exploration.

\section{E. Teaching Methods}

\section{Self reading group cooperation presentation}

\section{F. Preparation before Class}

The topic of this unit is art, and the reading part involves Western painting. Before the class, let the student groups cooperate to collect the information of Western painting by consulting books and searching online, understand the characteristics of Western painting, and organize the materials in groups.

\section{G. Teaching Process}

Step 1 Introduction

(1)Talk about art and western paintings.

(2)Learn and enjoy some western painters and their famous paintings.

The introduction is mainly to create a classroom atmosphere, inspire students' thinking, connect new and old knowledge, and stimulate students' interest in participating in classroom learning. The teacher introduces western painting from the unit title to let the students talk about what they know about western painting, and what's the difference with Tibetan Thangka. After that, the teacher introduces some famous Western painters and their works, guides the students to observe and find out the changes of Western painting in different periods, inspires the students to think about why there are such changes in Western painting, and start reading with such problems. In the process of introduction, students perceive the characteristics of Western painting, combine the original knowledge, think about the internal connection, and stimulate learning motivation.

Step 2 Task presentation

(1) Read for general ideas

(1) This passage is about the short history of western paintings.

(2) The information in the text is organized in time order. 
(3) The structure of the text is

(2) Read for the details

Students read the passage carefully and finish the chart.

\begin{tabular}{|c|c|}
\hline Period & Characteristics \\
\hline The Middle Ages & $\begin{array}{l}\text { 1.represent } \\
\text { 2.paint ___ in a ____ way }\end{array}$ \\
\hline The Renaissance & $\begin{array}{l}\text { 1.concentrate } \\
\text { 2.adopt } \\
\text { 3.return to } \\
\text { 4.paint } \\
\text { 5.two great discoveries: } \\
\text { 6. Why are they so important? (underline the answers in the text) }\end{array}$ \\
\hline Impressionism & $\begin{array}{l}\text { 1. What led to new painting styles in impressionism? (underline the answers in the text) } \\
\text { 2.break away from } \\
\text { 3.paint } \\
\text { 4.show } \\
\text { 5.not } \\
\text { 6.people's reaction to the paintings: }\end{array}$ \\
\hline Modern art & $\begin{array}{l}\text { 1.accepted as } \\
\text { 2.Modern art styles are } \\
\text { 3.Modern art is } \\
\text { 4.Modern art is } \\
\text { 5. What a big difference did the impressionists make on modern art? (underline the answer in the } \\
\text { text) }\end{array}$ \\
\hline
\end{tabular}

Task presentation is mainly to refine teaching objectives, show learning tasks and clarify teaching activities. The teaching task is the concrete reflection of the teaching goal and the basic basis of the teaching activity. Teaching tasks should be carefully designed, presented to students completely and accurately, attracted students' attention, improved participation in classroom learning, and effectively carried out reading teaching. This part of the teaching is designed for two parts: one is to understand the general idea and structure of the article through reading the article; the other is to find out the details of the information and have a comprehensive understanding of the article.

Step 3 Cooperative inquiry

(1) Read for use

Suppose you are a tour guide in a famous museum, now you are introducing one of the paintings below to the visitors. Make a dialogue with your partners and your conversation should include the following aspects.

(1)Brief description of the paintings

(2) The period the paintings belong to

(3) The characteristics of the paintings

(4)Feelings and thought about the paintings

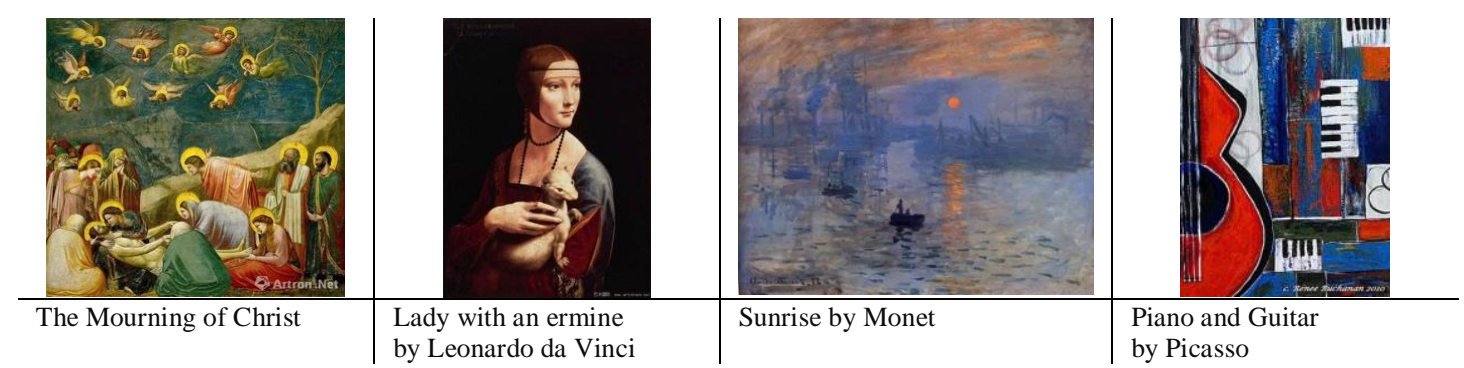

(2) Read for thinking

Work in groups and discuss the reasons why there are so many western paintings styles.

Cooperative inquiry is mainly to create problem situations, encourage to question and construct knowledge networks (Zhang Lanting, 2018). Teachers should actively create a pleasant and harmonious atmosphere of cooperative learning, encourage students to think actively and ask questions enthusiastically, guide students to dare to ask, and express their own opinions, so as to stimulate students' interest in inquiry and improve students' ability of inquiry. In the first cooperative activity, after students understand some Western painting knowledge through reading the article, they need to have a real experience to use what they have learned. Students can be Museum commentators and introduce a famous Western painting together with their companions. They can actively explore, actively cooperate and apply what they have learned. The second group activity is to ask students to understand the article in depth, combined what they have learned with the information about western painting consulted before class, and explore the reasons for the diversity of 
Western painting by group cooperation (Yang Jiaping,2017). Through this kind of cooperation, we can construct knowledge network, cultivate thinking ability, and make students learn to analyze and solve problems in communication.

Step 4 Students' presentation

(1) Role play

Students present the dialogue in groups.

Possible version (take the first painting for example):

Student A (the tour guide): Welcome to our museum. The painting you are looking at is The Mourning of Christ by the famous Italian painter Giotto di Bondone.

Student B (a visitor): The man lying on the ground is Christ, right?

Student A: Yes. He is dead, so many his believers feel sad. Look at their facial expressions. There are three kinds of Christ's believers, can you see?

Student C (a visitor): I know. Angels, gods and goddess, and humans. Humans have no halo over their heads.

Student A: You are right. This painting belongs to the Middle Ages, during which the main aims of painters was to represent religious theme to show respect and love for God.

Student D (a visitor): Well. In this picture, I can feel the sadness of every Christ's believer, who is drawn wonderfully and vividly.

Student A: I quite agree. Giotto di Bondone painted religious scenes in a more realistic way.

Student B (a visitor): I think this painting is also beautiful and colorful.

Student A: Ok! Now let's go and enjoy other paintings.

(2) Presentation

One representative of each group shares their opinions by the mind map.

Collect and summarize the students' ideas, as follows:

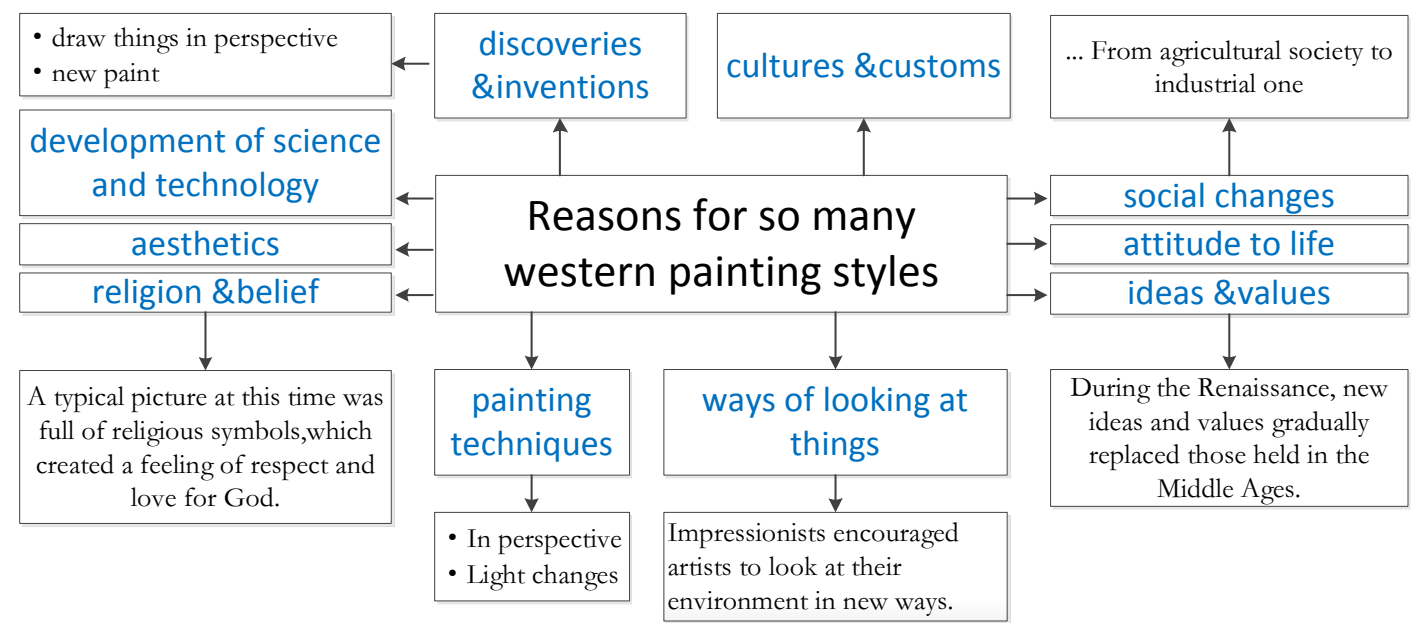

Students' presentation is to build a display platform, exchange and share results, and improve students' learning ability. It is a basic idea of the new curriculum to return the classroom to the students and let them become the main role of the classroom. The students' presentation based on cooperative inquiry is an important platform to show students' talent and personality, and an important measure to enhance students' learning confidence and promote their learning ability. Students explore and use the display platform to show and challenge themselves through self-study and group cooperation. The performance of dialogue gives each member of the group a chance to show themselves with clear division of labor and strong creativity and operability. The group representatives share the collective wisdom in the group, exchange and discuss, collide with the sparks of ideas, broaden their mind and improve their thinking ability(Wu Chen, Hao Qing, Xu Yunhao, Jiang Nan, Huo Hao,2017). The application of mind map enables students to sort out and summarize the fragmented information and form a logical network map, which is helpful to train students' logical thinking and divergent thinking.

Step5 Summary and evaluation

(1) Students' evaluation

Students make comments on the presentation of each group.

(2) Teachers' evaluation

(1) The teacher evaluates the students' performance.

(2) The teacher summarizes the whole class.

Western paintings have changed many times, and we have mainly learned about paintings in the Middle Ages, paintings in the Renaissance, Impressionist paintings and paintings of Modern Art, which shows us different social changes, people's ideas and values, various painting techniques and so on. No one knows what painting styles there will be in the future.

Art is for everyone and it exists everywhere. When it comes to appreciating an art painting, there is no right or wrong way. It is not how much you understand it but what you have gained from it that matters. 
Summary and evaluation is mainly to sort out the context of knowledge, feedback teaching effect and promote teaching reflection. Classroom summary is also a process of teaching evaluation, which can trigger self-reflection of teachers and students, and then make an objective and real teaching evaluation of classroom teaching. Students' evaluation of students is a kind of affirmation and encouragement to the learning participation and performance of their peers, which can be make each other closer. Teachers' comments are more instructive. The teacher's summary about this lesson is also a review of the whole teaching process and an evaluation of the whole teaching.

Step6 Homework after class

Prepare one of your favourite paintings or your favourite art form and share it with us next class.

Homework is still around the theme of art. Students prepare their favorite works of art and introduce them to the whole class in English next class. It can not only expand students' understanding of Art (music, painting, calligraphy, Thangka, paper cutting, carving, etc.), but also help students further understand each other, and at the same time help students practice oral English.

\section{CONCLUSION}

In English teaching, the cooperative inquiry teaching mode gives full play to the students' subjectivity, pays attention to the cultivation of students' ability of independent thinking, encourages students to explore and learn from each other, so as to achieve the purpose of improving students' ability of comprehensive use of English. Therefore, in English teaching, teachers should continue to carry out the practice and exploration of teaching reform, improve and perfect the teaching mode of group cooperative inquiry, comprehensively stimulate students' interest in English learning, and improve students' English learning a ability more efficiently. For Tibetan college students, it can help them to learn English and Mandarin in the same way, which will greatly help their language ability.

\section{ACKNOWLEDGEMENTS}

Gansu Province Education Science Planning Project (No.GS [2016] GHB0203),

The research projects of the social science and humanity on Young Fund of the ministry of Education (No.17YJCZH057)

Supported by the Fundamental Research Funds for the Central Universities. (NO : 31920190059)

Gansu Provincial First-class Discipline Program of Northwest Minzu University (NO.11080305)

\section{REFERENCES}

[1] Cai Yuqiu. (2014). Research on the Construction of Cooperative Learning Mode in College English Classroom Teaching. Journal of Jiamusi Vocational College, 12, 52 - 53.

[2] Ding Qun. (2018). Building a Cooperative Learning model in College English Teaching. Industry and Technology Forum, V.17, $14,175-176$.

[3] Liu Yujing. (2014). Research on Cooperative Learning Mode in College English Teaching. Academic Park, 30, 75-76.

[4] Wu Chen, Hao Qing, Xu Yunhao, Jiang Nan, Huo Hao. (2017). Research on the Construction, Operation and Evaluation of Curriculum Groups in Colleges and Universities -- Taking China Institute of labor relations as an example. Labor security world.18, 65-67.

[5] Yang Jiaping. (2017). Research on the Current Situation and Effective Mode of Group Learning of University Courses. Time Finance. 5,300-301

[6] Zhao Lanting. (2018). Formation Strategy of Cooperative Learning Group. Teaching and Management. 30, 23 - 25

Shengyin Zhu born in Wuwei, Gansu Province, in 1979, was admitted to Northwest Minzu University in 2017 to study for a doctorate in Chinese minority language and literature. His research direction is linguistics and applied linguistics. He is a member of the Chinese information society and a practice teacher of master students in Northwest Minzu University.

Xiangzhen He senior experimenter, doctor. He is a full-time experimenter in the Key Laboratory of Chinese national language and information technology of the State Ethnic Affairs Commission and the Ministry of Education. He is engaged in the research of Tibetan information technology.

Yerong Hu was born in Hebei Province in 1995. Received her bachelor's degree in software engineering from Tiangong University in 2019. She is now studying for a master's degree of China's Ethnic Languages and Information Technology of Ministry in Northwest Minzu University.

Yihao Zhang was born in Shanxi Province in 1996. Received the bachelor's degree in software engineering from Shanxi University in 2018. He is now studying for a master's degree of China's Ethnic Languages and Information Technology of Ministry in Northwest Minzu University. 